Kybernan : Jurnal Studi Kepemerintahan

Vol. 2 No. 2 Bulan September 2019

P-ISSN: 2502-2539/ E-ISSN: 2684-9836

\title{
Model Collaborative Governance Dalam Pelaksanaan Program Desa Online Di Kabupaten Pohuwato
}

\author{
Suaib Napir ${ }^{1}$, Yoslan K. Koni² \\ ${ }^{1}$ Universitas Gorontalo, ${ }^{2}$ Universitas Gorontalo \\ e-mail : suaibnapir9@gmail.com
}

\begin{abstract}
Abstrak: Praktek kolaborasi pemerintahan di Indonesia telah menjadi trend baru dalam kajian pemerintahan untuk mengkaji hubungannya good village governance. Tujuan penelitian ini ialah untuk mengetahui dinamika, aksi dan dampak collaborative governance dalam pelaksanaan desa online pada 8 desa di Kabupaten Pohuwato. Penelitian ini diarahkan pada kolaborasi multipihak dalam program percepatan pembangunan berbasis desa online meliputi informasi, baik pengembangan potensi maupun masalah mendasar dalam tata kelola pemerintahan desa Kabupaten Pohuwato. Penelitian ini menggunakan metode penelitian kualitatif dengan teknik Purposive Sampling digunakan karena teknik penentuan sumber data dengan pertimbangan tertentu. Melalui metode tersebut, data yang diperoleh akan lebih mendalam. Pengumpulan data dilakukan dengan tiga cara yakni Studi Pustaka (Library Research), Studi Lapangan (Field Research), Focus Group Discution (FGD). Hasil penelitian, yaitu, pertama, model collaborative governance belum optimal dalam pelaksanaan program desa online di kabupaten Pohuwato karena eksistensinya belum memiliki dampak yang sifnifikan terhadap perkembangan informasi dan pembangunan desa. Kedua, pengaruh program desa online belum maksimal terhadap percepatan pembangunan desa Kabupaten Pohuwato karena sector strategis, baik potensi dan masalah tidak dimasukkan kedalam informasi program desa on line. Namun kegiatan-kegiatan yang sifat universal saja yang diinformasikan dan itu tidak berpengaruh pada percepatan pembangunan desa di Kabupaten Pohuwato
\end{abstract}

Kata kunci: Collaborative Governance, Desa Online.

Abstract: The practice of government collaboration in Indonesia has become a new trend in government studies to examine the relationship between good village governance. The goal of the study was to determine the dynamics, action, and impact of collaborative governance in the implementation of an online village in 8 villages in Pohuwato County. This research is aimed at multi-party collaboration in an online village-based development acceleration program including information, both potential development and fundamental problems in the governance of Pohuwato Regency Village. This research uses qualitative research methods with Purposive Sampling technique. The selection of qualitative methods with purposive sampling techniques is used because of data source determination techniques with certain considerations. Through these methods, the data obtained will be more profound. Data collection is done in three ways, namely Library Research, field Research, Focus Group Discussion (FGD).The results of the study are expected, that is, first, the model of collaborative governance is not optimal in the implementation of the online village program in Pohuwato District because its existence has not had an impact on the development of information and Village development. Secondly, the influence of online village program is not maximal to accelerating the development of Pohuwato District Village because of strategic sectors, both potential and problems are not incorporated into the village program information online. However, the activities of universal nature are informed and it does not effect on accelerating the development of the village in Pohuwato District

Keywords: Collaborative Governance, village Online. 


\section{Pendahuluan}

Perkembangan

tata kelola pemerintahan desa yang berdimensi collaborative governance (tata kelola pemerintahan kolaboratif) menjadi trend dan fenomena baru yang menarik diteliti dan dikaji. Di Indonesia, inisiasi pemerintahan desa dalam bentuk collaborative governance mulai berkembang pasca pengesahan regulasi UU Nomor 6 Tahun 2016 tentang desa yang lebih memberikan ruang desentralisasi desa secara penuh. Sampai saat ini, praktek kolaborasi antara pemerintah, swasta dan masyarakat berkembang pesat di berbagai pemerintah daerah berbasis kota besar seperti Jakarta, Surabaya, Medan dan Makassar sedang mempraktekkannya dengan konsep dan prinsip yang relatif sama. Sementara praktek kolaborasi pemerintahan desa masih kurang, padahal Collaborative governance sendiri telah dikembangkan selama dua dekade terakhir (Ansell dan Gash, 2007:543).

Dampak collaborative governance dalam penelitian ini terletak pada aspek struktur, proses dan dampak tata kelola pemerintahan dan pembangunan desa. Aspek tersebut menjadi daya tarik tersendiri untuk dikaji guna mengetahui yang mana best practices (praktek-praktek terbaik) dan worst practices (praktek-praktek terburuk). Pengkajian fenomena ini karena collaborative governance merupakan instrumen kebijakan public yang dapat berdampak pada tata kelola pemerintahan desa (Gray dkk, 2003:8). Konsep collaborative governance dalam pelaksanaan program desa online merupakan suatu keharusan dalam tata kelola pemerintahan desa. Konsep ini merupakan upaya kerjasama dan hubungan sinergis yang bersifat mutlak dalam domain governance (Budiati, 2012:5). Sisi lain, Organisasi pemerintah dan non-pemerintah perlu mulai mengedepankan apa yang disebut tata kelola kolaboratif pemerintahan desa (collaborative village governance) dalam percepatan pembangunan desa di Indonesia.

Program unggulan collaborative village governance saat ini adalah program desa membangun. Peluncuran program desa online merupakan komitmen nyata pemerintah pusat.dalam mendorong pembangunan desa. Program desa online merupakan program prioritas dalam percepatan informasi tentang desa, sehingga potensi desa, produk unggulan desa, dan progres pembangunan desa bisa dipromosikan dan diakses dengan mudah. Karena itu perlu collaborative governance dalam program desa online karena pemerintah menargetkan minimal 5000 desa telah mengimplementasikan program desa online untuk percepatan pembangunan desa di Indonesia saat ini. Desa online diharapkan menjadi sarana sarana transparaansi desa karena menyediakan ruang kepada pihak pemerintah desa Laporan tentang rencana pembangunan desa, pengelolaan Dana Desa, dan progres pembangunan desa pada 8 desa di Kabupaten Pohuwato.

Penelitian collaborate governance ditingkat desa masih sangat kurang, sehingga tidak semua upaya yang dilaksanakan sejalan dengan harapan yang ditargetkan. Collaborative governance $\mathrm{di}$ desa masih jarang diperbincangkan. Ini berdasar pada beberapa praktek kolaborasi antara pemerintah pusat dan desa, dan masyarakat dalam pengendalian desa on line 
yang masih mengalami berbagai macam kendala. Ironinya, bila diamati secara mendalam, masih banyak fenomena problematis yang terlihat sejak program ini dilaksanakan. Sampai saat ini pelaksanaan program desa online belum juga membawa desa pada percepatan pembangunan desa di Kabupaten Pohuwato.

Permasalah penelitian ini tentang bagaimana model Collaborative governance dalam pelaksanaan program desa online di kabupaten Pohuwato dan pengaruh program desa online dalam percepatan pembangunan desa di kabupaten Pohuwato. tujuan penelitian yaitu untuk mengetahui model Collaborative governance dalam pelaksanaan program desa online di kabupaten Pohuwato dan menganalisis pengaruh parogram desa online dalam percepatan pembangunan desa di Kabupaten Pohuwato. Urgensi kajian collaborative governance dalam pelaksanaan program desa online tersebut diharapkan memberikan kontribusi positif dalam percepatan pembangunan desa di Kabupaten Pohwato.

\section{Metode Penelitian}

Penelitian ini menggunakan pendekatan penelitian kualitatif. Selanjutnya data yang ditelusuri meliputi data primer dan sekunder. Metode yang digunakan untuk menentukan sumber data dalam penelitian ini adalah Purposive Sampling yaitu teknik Dengan metode Purposive Sampling maka sumber data dalam penelitian ini adalah pelaksanaan desa online pada 8 desa di Kabupaten Pohuwato. Instrumen pengumpul data terbagi menjadi dua yakni untuk data primer menggunakan wawancara dan kuesioner. Wawancara ini dilakukan dengan indepht interview, yaitu metode pengumpulan data melalui wawancara yang dilakukan secara mendalam kepada sumber data (W.Gulo, 2003: 119).

Teknik analisis datapenelitian terdiri dari: (a) Reduction data, verifikasi data untuk kepentingan penyederhanaan data dalam rangka lebih mempertajam data yang dibutuhkan; (b) Display Data, menyajikan data secara terorganisir dan sistematis, sehingga membentuk suatu kompoen yang utuh dan terpadu; serta (c) Conclusion, melakukan interpretasi data sebagai langkah penentuan dalam penarikan kesimpulan. Penarikan kesimpulan merupakan upaya untuk mencari arti dari data yang dicatat dan disajikan. Analisis data ini mengadobsi model analisis data yang dikembangkan oleh Milles dan Hiberman (1992).

\section{Hasil Penelitian dan Pembahasan}

\section{a. Model Collaborative Governance Dalam Pelaksanaan Program Desa Online di Kabupaten Pohuwato.}

Program desa online di Kabupaten Pohuwato yang menjadi percontohan adal delapan desa. Semua desa itu adalah desa yang penduduknya merupakan warga transmigrasi asal berbagai daerah di pulau Jawa, Bali, serta warga lokal. Kedelapan desa tersebut adalah Panca Karsa 1, Panca Karsa 2, Malango, Makarti Jaya, Tirto Asri, Kalimas, Puncak Jaya di Kecamatan Taluditi dan Desa Manunggal Karya di Kecamatan Randangan. Semua desa tersebut sudah memiliki situs sesuai dengan nama desa, seperti www.tirtoasri.desa.id yang mulai menampilkan kegiatan dan potensi desanya. Demikian juga desa-desa yang lainnya juga melakukan hal yang sama. 
Menurut Mariana (Operator desa pancakarsa, 2019), kapasitas sumber daya manusia operator desa.id dilatih untuk menggunakan aplikasi internet oleh Kementerian Kominfo untuk pembuatan website dan cara menulis berita atau informasi untuk mengisi website. website tersebut menampilkan profil desa Panca Karsa dan potensinya. Produk unggulan dan potensi desa di kawasan transmigrasi yang dipublikasikan ini diharapkan dapat mengangkat perekonomian desa dan kesejahteraan masyarakatnya. Potensi desa di Kabuoaten Pohuwato, dari sektor pertanian dan peternakan menjadi unggulan masyarakat desa. Selain itu, keindahan alam dan budayanya juga diharapkan akan mendorong sektor pariwisata.

UU Nomor 6 tahun 201 tentang Desa memberikan ruang kepada desa agar dapat secara utuh memiliki otonomi dalam menentukan arah pembangunan desa dan memberikan kesempatan dalam menguatnya otonomi asli desa yang berbasis pada nilai sosial dan identitas kearifan lokal pedesaan. Sejak tahun 2014 Percepatan pembangunan desa telah didorong oleh pemerintah melalui kebijakan dan program pembangunan desa. Sistem informasi desa di Kabupaten Pohuwato sebagaimana yang dimaksud dalam undang undang desa tersebut dimaksudkan sebagai wujud implementasi $e$ government ditingkat pemerintahan desa. Sistem ini dikelola oleh Pemerintah Desa di Kabupaten Pohuwato dan dapat diakses oleh masyarakat Desa dan semua pemangku kepentingan. Program desa online tidak terlepas dari penggunaan internet sebagai pemanfaatan teknologi informasi untuk sumber informasi masyarakat. Menurut
Sutabri (2012-8), Internet merupakan perpaduan teknologi informasi dan teknologi komputer. Internet membuat perubahan hidup masyarakat, pemasaran berbagai produk untuk mendapatkan nilai ekonomis yang lebih tinggi dan kemudahan mencari informasi. Selain itu, internet juga menjadi sumber kejahatan baru, seperti hacking, cracking, spamming.

Penggunaan website desa online Di Indonesia diatur dalam Peraturan Menteri Komunikasi dan Informatika Nomor 28 /PER/M.KOMINFO/9/2006 tentang Penggunaan Nama Domain go.id. program tersebut guna menunjang pengembangan dan pelaksanaan e-government. Portal/ web desa telah resmi di-release extensi domain baru .DESA.ID oleh PANDI sebagai otoritas pengelola alamat domain Indonesia pada tanggal 1 Mei 2013. Program ini mulai berjalan di Kabupaten Pohuwato sejak tahun 2016 hingga saat saat ini. Sampai sekarang domain tersebut terus bertambah seiring dengan terbitnya Undang undang Nomor 6 Tahun 2014 tentang Desa. Berikut ini perkembangan jumlah domain desa.id berdasarkan data dari desa online di Kabupaten Pohuato. Perkembangan jumlah domain desa.id adalah pada Tabel 4.1.

Berdasarkan data perkembangan domain diatas terlihat terjadi peningkatan yang signifikan terhadap pemanfaatan domain desa.id tersebut. Namun pada awal 2016 sempat terjadi penurunan jumlah domain tersebut sebanyak 5 domain. Penurunan terjadi karena kadaluarsa pada beberapa alamat domain tersebut. Pada tahun selanjutnya sempat terjadi juga penurunan jumlah domain desa.id cukup drastis. Hal ini disebabkan administrator pengurus domain tidak melakukan 
pembayaran terhadap domain yang dimiliki sebagai salah satu syarat untuk pendaftaran ulang domain. Selain itu, pengaruh kapasitas sumber daya manusia juga yang belum memadai dalam mengendalikan disa.id di Kabupaten tersebut.

Aplikasi desa online bisa dikatakan sebagai gerbang untuk masuk ke masingmasing website desa yang sudah terdaftar sejak diluncurkan pada tahun 2016 di Kabupaten Pohuwato. Pada dasarnya Portal Desa Online berisi peta sebaran website desa online, konten agregasi kegiatan desa, dan konten agregasi produk unggulan desa, dan konten permasalahan utama desa di Kabupaten Pohuwato.
Secara umum konten aplikasi desa online bisa menjadi sarana promosi yang bagus dan telah dipersiapkan dengan matang. Selain itu konten aplikasinya juga dapat menjadi sumber pengambilan kebijakan pemerintah yang terkait dengan desa. Hal ini bisa terlihat berdasarkan data dari Kementerian Desa, Pembangunan Daerah Tertinggal dan Transmigrasi per maret 2017 telah ada 1125 desa mendaftarkan desanya untuk ikut berpartisipasi dalam program desa Online dan berharap desanya akan lebih maju melalui sarana promosi yang ditawarkan.

Tabel 4.1 Desa on line di Kabupaten Pohuwato

\begin{tabular}{|c|c|c|c|}
\hline No & Desa & Website & Ket \\
\hline 1 & Panca Karsa & pancakarsa.desa.id & $\begin{array}{c}\text { K. Aktif 15 } \\
\text { januari 2018 }\end{array}$ \\
\hline 2 & Panca Karsa II & pancakarsa2.desa.id & $\begin{array}{c}\text { Aktif 13 februari } \\
2019\end{array}$ \\
\hline 3 & Malango & malango.desa.id & $\begin{array}{c}\text { K. Aktif 20 } \\
\text { november 2018 }\end{array}$ \\
\hline 4 & Tirto Asri & tirtoasri.desa.id & $\begin{array}{c}\text { Aktf 4 desember } \\
2018\end{array}$ \\
\hline 5 & Makarti Jaya & makartijaya.desa.id & $\begin{array}{c}\text { K. Aktif 11 } \\
\text { januari 2018 }\end{array}$ \\
\hline 6 & Kalimas & kalmias.desa.id & $\begin{array}{c}\text { Aktif 14 januari } \\
2019\end{array}$ \\
\hline 7 & Puncak Jaya & $\begin{array}{c}\text { puncakjaya- } \\
\text { taluditi.desa.id }\end{array}$ & $\begin{array}{c}\text { Aktif 17 Deseber } \\
2018\end{array}$ \\
\hline 8 & Manunggal Karya & manunggalkarya.desa.id & Aktif Maret 2019 \\
\hline
\end{tabular}

Sumber: Hasil olah data primer, 2019 
Dari tabel diatas dapat kita lihat bahwa sudah ada desa di 8 desa di Kabupaten Pohuwato yang sudah memanfaatkan fasilitas desa online. Desa yang memanfaatkan fasilitas desa online mengisyaratkan bahwa aplikasi desa online cukup mudah dipahami dan digunakan sebagai sarana desa dalam memperkenalkan desa dan potensinya. Desa yang ingin menggunakan fasilitas desa online dapat melakukan registrasi dengan beberapa persyaratan. Namun dalam menggunakan desa online, tidak sertamerta hanya dengan registrasi dan langsung digunakan, akan tetapi perlu ada pengenalan terhadap sistemnya. Oleh karena itu, perlu dilakukan pelatihan kepada aparat desa agar pemanfaatan sistem aplikasi desa online dapat

optimal.

\section{Gambar 1. Model Desa Online di Kabupaten Pohuwato}

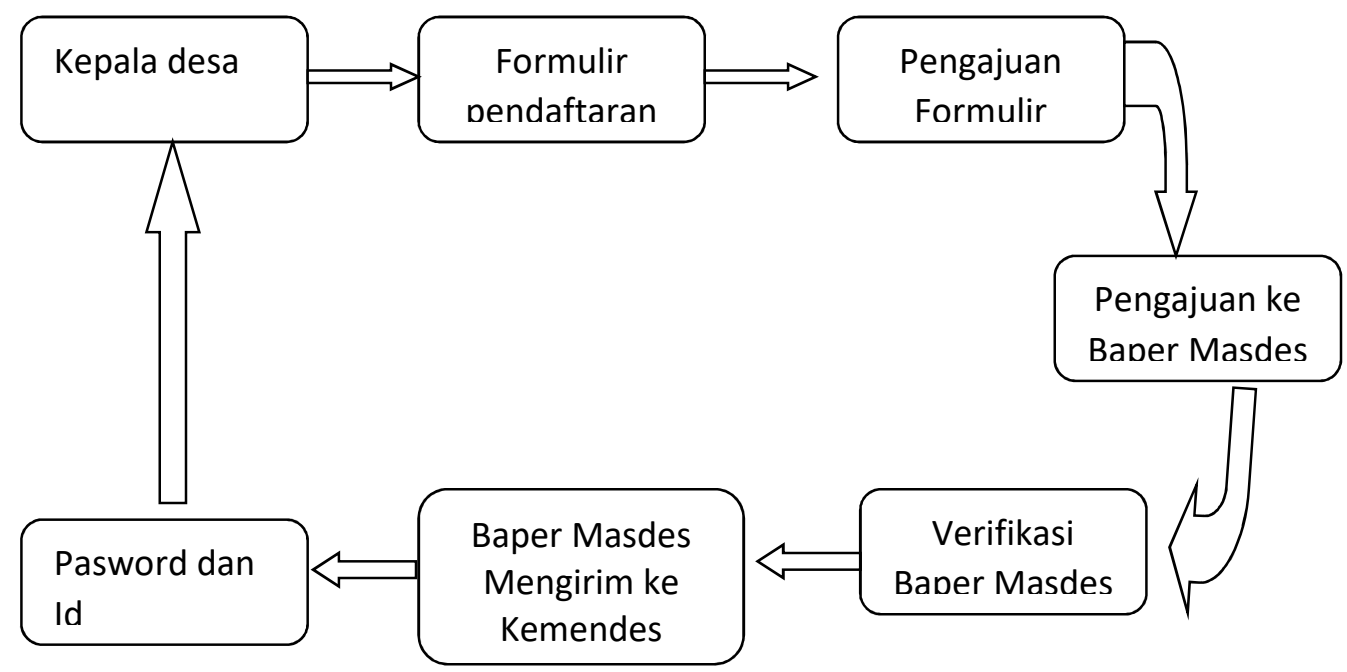

Desa yang berpartisipasi dalam aplikasi desa online ini akan memiliki admin desa yang bertanggungjawab atas segala aktifitas dalam sistem aplikasi desa online. Admin desa ini juga harus menjamin agar informasi yang tersedia dalam sistem desa online merupakan informasi yang benar dan sah dari desa. Selain sebagai sarana peningkatan daya saing melalui promosi produk unggulan desa, sistem aplikasi desa online dirancang juga agar masyarakat mudah mengontrol penggunaan anggaran desa. Hal ini dikarenakan program desa online yang menjadi dasar dibangunnya sistem ini mengacu pada Undang Undang Nomor 6 Tahun 2014 Tentang Desa. Dalam undang undang tersebut telah diamanatkan agar pemerintah mengembangkan data dan informasi untuk dapat diakses masyarakat dengan mudah. Sistem ini juga menjadi upaya pemerintah untuk merealisasikan keterbukaan informasi yang berkaitan dengan desa.

Potensi unggulan seperti pariwisata, wahana hiburan rakyat, produk kerajinan warga desa, produk olahan makanan, produk pertanian dan potensi sumber daya alam juga menjadi data yang diperlukan 
informasinya sebagai gambaran peta kekuatan dan keunggulan desa dalam mempercepat pembangunan desa. Hal ini menjadi modal awal dalam meningkatkan daya saing masyrakat desa. Dalam acara Sosialisasi Aplikasi Desa Online Tahun 2016 seperti yang ditulis dalam website pemerintah kabupaten Pohuwato menyebutkan bahwa aplikasi portal desa merupakan sarana untuk berkomunikasi dan membuka cakrawala terhadap ilmu pengetahuan. Sistem atau aplikasi tersebut membuat satu wilayah dengan satu wilayah lain tidak ada batasnya, yang selama ini kita gunakan batas administrasi, tetapi pada teknologi tidak dibatasi oleh adminstratif dan waktu, saat itu informasi yang ada di Pusat saat itu juga kita didaerah mendapatkan informasi tersebut. b. Pengaruh Program Desa Online Dalam Percepatan Pembangunan Desa di Kabupaten Pohuwato

Desa online merupakan program kementerian desa dan daerah tertinggal repulik Indonesia. Program ini menggunakan domain desa.id untuk memuat seluruh informasi yang berhubungan dengan pedesaan di Kabupaten Pohuwato. Sebanyak delapan desa di Kabupaten Pohuwato menjadi percontohan program desa online, dinataranya desa Panca Karsa 1, Panca Karsa 2, Malango, Makarti Jaya, Tirto Asri, Kalimas, Puncak Jaya di Kecamatan Taluditi dan Desa Manunggal Karya di Kecamatan Randangan. Desa tersebut telah memiliki situs sesuai dengan nama desa, seperti www.tirtoasri.desa.id yang mulai menampilkan kegiatan dan potensi desa. Desa-desa lainnya juga melakukan hal yang sama, namun ada desa yang aktif dan adapula desa yang sudah tidak aktif menampilkan informasinya melalui program desa online. Adapun aktifitas desa online pada 8 desa di Kabupaten Pohuwato dapat dilihat pada 4.2.

Tabel 4.2 Aktifitas desa online di Kabupaten Pohuwato

\begin{tabular}{|l|l|l|l|}
\hline No & \multicolumn{1}{|c|}{ Desa } & \multicolumn{1}{c|}{ Website } & \multicolumn{1}{c|}{ Ket } \\
\hline 1 & Panca Karsa & pancakarsa.desa.id & kurang aktif \\
\hline 2 & Panca Karsa II & pancakarsa2.desa.id & Aktif \\
\hline 3 & Malango & malango.desa.id & Kurang aktif \\
\hline 4 & Tirto Asri & tirtoasri.desa.id & Kurang Aktf \\
\hline 5 & Makarti Jaya & makartijaya.desa.id & Kurang Aktif \\
\hline 6 & Kalimas & kalmias.desa.id & Aktif \\
\hline 7 & Puncak Jaya & $\begin{array}{l}\text { puncakjaya- } \\
\text { taluditi.desa.id }\end{array}$ & Kurang Aktif \\
\hline 8 & Manunggal Karya & manunggalkarya.desa.id & Aktif \\
\hline
\end{tabular}

Sumber: Hasil olah data primer, 2019 
Table 4.2 menunjukkan bahwa terdapat 3 desa yang masih aktif program desa online nya, yaitu desa Panca Karsa2, Kalimas, dan Manunggal Karya, sementara 5 desa lainnya program desa onlinenya sudah kurang aktif. Hal ini menunjukkan bahwa program desa online di Kabupaten Pohuwato kurang maksimal dalam mendukung percepatan pembangunan desa. Bisa dilihay pada desa panca Karsa 1 bahwa program desa online sejak januari 2018 sudah kurang aktif. Hal ini menyebabkan program desa online tidak dapat menjadi sumber utama bagi pemerintah daerah dan pemerintah pusat untuk tidak dapat merespon informasi desa dalam mewujudkan perecepatan pembangunan desa.

Program desa online juga kurang aktif pada desa Malango, Tirto Asri, Makarti Jaya, dan Puncak Jaya. Domain desa yang kurang aktif juga tidak dapat memberikan informasi yang lengkap terkait dengan kondisi pembangunan desa. Padahal informasi tersebut sangat dibutuhkan karena dalam Undang-Undang Nomor 6 Tahun 2014 tentang Desa memuat dua kewajiban yang sangat penting. Pertama, nilai alokasi Anggaran yang diperuntukkan ke desa nilainya sebesar $10 \%$ dari dan diluar dana transfer daerah. Sederhananya jika Anggaran Belanja Negara (APBN) Tahun 2014 mencapai 590,2 Triliun, maka alokasi anggaran desa untuk seluruh Indonesia harusnya bisa mencapai 59,02 Triliun. Kedua, Selain bersumber dari APBN, desa juga memiliki potensi yang luar biasa yang bersumber dari desa itu sendiri. Dukungan Anggaran Pemerintah terus bertambah, sehingga potensi pembangunan desa melalui desa online diharapkan dapat diinformasikan secara maksimal.

Menuru Miranti (2019) menyatakan bahwa dalam mendorong peran desa online dalam percepatan pembangunan di Kabupaten Pohuwato, maka para sarjana dari masyarakat desa Kabupaten Pohuwato lulusan perguruan tinggi tidak perlu lagi beramai-ramai menuju dan tinggal di kota. Waktunya para sarjana tersebut kembali kedesa masing-masing untuk membangun kampung halaman mulai hal-hal sederhana, tetapi memiliki manfaat yang besar untuk pembangunan desa. Pemuda desa sudah harus berpikir bagaimana membangun desa, jika lulusan ekonomi, mulai berpikir membangun usaha produktif yang dapat memberdayakan ekonomi desa lewat badan usaha milik desa (BUMDES) agar menyamai industri perkotaan bahkan kalo bisa lebih berkembang. Jika seorang sarjana pertanian, mulailah berfikir mengembangkan pertanian dikampung masing-masing. Para lulusan sekolah guru, mari mengajar di kampung halaman dan mulai memberikan pendidikan yang baik bagi anak-anak desa, demikian pula lulusan sarjana politik suda waktunya membangun tatanan politik yang sehat di Kampung masing-masing untuk mengurang kebiasaan-kebiasaan yang kurang bernilai. Untuk pemuda dengan gelar Sarjana Komputer dan Komunikasi bergabunglah mewujudkan desa online sebagai bagian program percepatan pembangunan desa.

Menurut Agustriadi (2019), saat ini desa di Kabupaten Pohuwato membutuhkan seseorang yang terdidik untuk berkembang walau pada sisi tertentu juga sudah waktunya orang kota untuk belajar dari pesona keaslian desa dan tantangan 
kehidupan desa. Dengan demikian, desa tidak lagi dipandang sebagai objek yang hampa, tetapi desa dijadikan sebagai sarana harmonisasi antara kehidupan kota dan kearifan desa. Selain itu, Potensi besar yang dimiliki desa saat ini tidak cukup dengan dorongan kebijakan program desa online oleh pemerintah pusat saja, akan tetapi perlu ada penguatan pada tiga aspek, yaitu kelembagaan, aktor dan mekanisme pengawasan.

Pada aspek domain desa online masih memuat wacana yang bersifat universal. Padahal program desa online tersebut diharapkan menjadi pusat informasi inti tentang desa di Kabupaten Pohuwato. Peneliti menemukan bahwa bahwa konten dalam domain desa online masih bersifat informasi formal atau informasi berbasis kegiatan umum. Desa online diharapkan memuat informasi tentang potensi dan masalah inti desa di Kabupaten Pohuwato, sehingga informasi atau promosi desa dapat dengan mudah diketahui informasinya oleh pemerintah, baik pemerintah daerah maupun pemerintah pusat.

\section{Kesimpulan}

Hasil penelitian ini menunjukkan bahwa, pertama, model collaborative governance belum optimal dalam pelaksanaan program desa online di kabupaten Pohuwato karena eksistensinya belum memiliki dampak yang sifnifikan terhadap perkembangan informasi dan pembangunan desa. Kedua, pengaruh program desa online belum maksimal terhadap percepatan pembangunan desa Kabupaten Pohuwato karena sector strategis, baik potensi dan masalah tidak dimasukkan kedalam informasi program desa on line. Namun kegiatan-kegiatan yang sifat universal saja yang diinformasikan dan itu tidak berpengaruh pada percepatan pembangunan desa di Kabupaten Pohuwato.

\section{Daftar Pustaka}

—. 2 Mei 2017. Tentang domain baru DESA.ID. Tersedia online (https://www.rumahweb.com/berit a/tentang-domain-baru-desa-id diakses 10 maret 2017).

_. 2017. Desa Online. Tersedia online (http://desa.kemendesa.go.id/ diakses 10 maret 2017).

- 2017. Program Desa Online. Tersedia online

(http://awi.net.id/2016/12/20/pro gramdesa-online/ diakses 10 maret 2017).

Ansell, Chris, dan Gash, Alison, 2007, Collaborative Governance in Theory and Practice, Journal of Public Administration Research and Theory, Vol.18, hal.543-571. Diakses tanggal 29 Januari 2018, dari Oxford Journals (JPART).

APJII. 2016. Infografis Penetrasi dan Perilaku Pengguna Internet Indonesia 2016. Jakarta : APJII.

Budiati, L, 2012, Good Governance Dalam Pengelolaan Lingkungan Hidup, Bogor :

Ghalia Indonesia.Gray, Andrew, dkk, 2003, The Challenge for Evaluation, Collaboration in Public Service, New Jersey : Transaction Publishers. 
Indrajit, Richardus Eko. 2002. Electronic Government: Strategi Pembangunan dan Pengembangan Sistem Pelayanan Publik Berbasis Teknologi Digital. yogjakarta: ANDI Yogyakarta.

Le, S. Jin, dan Yoo, D. Sang, 2012, The Adoption of Collaborative Governance Institutions : The EPAStates Performance Partnership Agreements (PPAS), International Review of Public Administration, Vol. 17 (2), hal. 143-61. Diakses tanggal 22 Januari 2018, dari ABI/INFORM Complete.

Norman K. and Yvonna S. Lincoln. (2003). Handbook of Qualitative. Research. Thousand Oaks, California.

Richardo, Hans. 2016. Pengertian Website dan Internet. Tersedia Online (http://belajarbisnisinternet.com/p engertian-website-tiga-jeniswebsite-paling-umum/diakses $\quad 10$ maret 2017).

Silvia, Chris, 2011, Collaborrative Governance Concepts for Succesful Network Leadership, State and Local Government Review, Vol. 43 (1), hal. 66-71. Diakses tanggal 27 Januari 2018, dari SAGE Publication.

Sutabri, Tata. 2012. Komputer dan masyarakat. Jakarta: Agromedia Pustaka.

Sugiyono. (2005). Memahami Penelitian Kualitatif. Bandung: Alfabet.

Susanto, Mikke. 2004. Menimbang Ruang Menata Rupa. Jakarta: Agromedia Pustaka.
Wahyudi, Andi, etal. 2016. Peningkatan Kapasitas Desa. Samarinda: PKP2A III-LAN.

Padan, Yansen Tipa. 2014. Revolusi dari Desa. Jakarta: Kompas Gramedia.

Undang Undang Nomor 6 Tahun 2014 Tentang Desa

Undang Undang No. 23 Tahun 2014 Tentang Pemerintahan Daerah

Peraturan Menteri Desa, Pembangunan Daerah Tertinggal, Dan Transmigrasi Republik Indonesia Nomor 1 Tahun 2015 Tentang Pedoman Kewenangan Berdasarkan Hak Asal Usul Dan Kewenangan Lokal Berskala Desa. 